\title{
PROJECTION OF THE RUSSIAN ECONOMIC DEVELOPMENT IN THE FRAMEWORK OF THE OPTIMAL CONTROL MODEL BY INVESTMENTS IN FIXED ASSETS
}

In this paper, we develop an economic growth model taking into account two factors of production: fixed capital and labor force, to study the dynamics of GDP growth. The dependence of the output of these factors is described by a production function of the exponential type. Within the framework of the optimal control theory, the optimization problem for investment levels is being solved to maximize the integral index of con-

${ }^{1}$ (c) Tarasyev A. M., Usova A. A., Shmotina Yu. V. Text. 2014. 
sumption. We study the qualitative properties of optimal trajectories as solutions of the Hamiltonian systems arising in Pontryagin's maximum principle. The sensitivity analysis of the equilibrium solutions of the economic system is implemented with respect to the elasticity coefficients of the production function, the depreciation rate of the capital, and the discount factor, and growth trends are indicated. The econometric analysis of the model parameters is provided basing on real data for the Russian economy. In accordance with the results of the regression analysis, the projection of economic development is constructed in conditions of the applicability of the economic growth model.

Keywords: dynamic models of economic growth, optimal control, Pontryagin's maximum principle, economic equilibrium.

\section{Introduction}

This paper is devoted to analysis of the economic growth model based on methods of the optimal control theory with a view to construct the optimal investment strategies. The considered model in its design combines classical constructions of the economic growth theory [1], and advanced methods of analysis of the optimal control theory [2], in particular, generalizations of Pontryagin's maximum principle for problems with infinite planning horizon [3-11]. is Investments in fixed assets serve as control parameter and provide the output growth through the production function. In the balance equation the output is redistributed between consumption and investment, and this provides the model closedness in terms of control investment parameters. In this statement, the maximized characteristics is consumption, as in all classical models of financial investments [12], for example, in the Fisher stationary model and the Sharpe capital asset pricing model (CAPM) [13-14].

Application of the Pontryagin maximum principle in the model of economic growth generates the Hamiltonian system of differential equations, whose stationary points can be used to describe the equilibrium trajectories of an economy, and whose trajectories - to build prognostic estimates of economic development. It is important to emphasize that the main element of the solution is the optimal programming control which can be interpreted as an optimal investment plan. We develop high accuracy algorithms for constructing optimal investment plans as trajectories of the Hamiltonian systems.

The paper is organized as follows. The pattern of the economic growth model is given the optimal control problem is posed for investments in fixed assets. Qualitative analysis of solutions is provided within Pontryagin's maximum principle, stationary points are constructed for the Hamiltonian system generating economy equilibria and stationary optimal investment plans. In conclusion, the model parameters are set to the real data in the framework of the econometric analysis of the production function, which complements the study of the properties of the model Hamiltonian systems. A comparative analysis of the prognostic model trajectories and real time series is fulfilled on the basis of the Russian macroeconomic data. Basic trends of model trajectories are identified and the key differences between these trends are indicated against the growth trajectories trends of developed economies.

\section{Model of economic growth and the problem of optimal investment control}

The basis of the model in the production block is presented by the production function, which is considered in the dynamic process of economic development. The main variables of the model are levels of capital $K(t)$ and labor $L(t)$ at time $t$, and the production output $Y(t)$, which is given by the exponential production function of the Cobb-Douglas type [12]: $Y(t)=F(K(t), L(t))=a K^{\alpha}(t) L^{1-\alpha}(t)$. Here a positive parameter $\alpha$ corresponds to the output which is provided by production factors unaccounted in the model - Total Factor Productivity (TFP), and a nonnegative parameter $\alpha(0<\alpha<1)$ is the elasticity coefficient.

Using the property of the positive homogeneity of the first order ${ }^{1}$ for the production function, one can make transition to relative variables: capital $k(t)=K(t) / L(t)$ and GDP $y(t)=Y(t) / L(t)$ per one worker (per capita)

$$
\begin{aligned}
& y(t)=\frac{Y(t)}{L(t)}=\frac{F(K(t), L(t))}{L(t)}= \\
& =F\left(\frac{K(t)}{L(t)}, 1\right)=f(k(t))=a k^{\alpha}(t),
\end{aligned}
$$

where the function $y(t)=f(k(t))$ defines the labor productivity as a function of the capital-labor ratio.

Let us denote by symbols $C(t)$ and $I(t)$ consumption and investments in fixed assets at time $t$, respectively. Under assumption of the closedness of

\footnotetext{
${ }^{1}$ The property of the positive homogeneity of the first order is defined as follows $\forall v>0 F(\nu K, v L)=v F(K, L)$.
} 
an economic system, one should require the balance relation in each time period

$$
\begin{array}{r}
Y(t)=C(t)+I(t)=C(t)+u(t) Y(t) \Rightarrow \\
\Rightarrow c(t)=\frac{C(t)}{L(t)}=y(t)(1-u(t)),
\end{array}
$$

where the function $u(t)$ corresponds to the share of GDP invested in fixed assets, i.e. $I(t)=u(t) Y(t)$. The relative value of $c(t)$ is the level of consumption per one worker. One can derive restrictions on the investment levels from the balance equation,

$$
\begin{gathered}
0 \leq c(t)=y(t)(1-u(t))<y(t), \\
0 \leq u(t) \leq \bar{u}<1 .
\end{gathered}
$$

This version of the model assumes that the growth of the capital stock $K(t)$ is subject to the dynamics introduced by Solow [1]

$$
\begin{gathered}
\dot{K}(t)=u(t) Y(t)-\mu K(t), K(0)=K_{0}, \\
\frac{\dot{L}(t)}{L(t)}=n, L(0)=L_{0},
\end{gathered}
$$

where a positive coefficient $\mu$ is the depreciation rate of capital, and a constant value of $n$ stands for the growth rate of the labor force $L(t)$.

Passing to the relative values in the last relations, we obtain the following dynamics for $k(t)$

$$
\dot{k}(t)=u(t) f(k(t))-\delta k(t), k(0)=k_{0}=\frac{K_{0}}{L_{0}}
$$

where the parameter $\delta=\mu+n$ is the degree of capital dilution due to its depreciation and increase in the labor force.

Let us consider the problem of optimal control of investment in which the objective functional is given by the integral of the logarithmic index of consumption, discounted on the infinite time interval:

$$
\begin{aligned}
& J(\cdot)=\int_{0}^{+\infty} e^{-\rho t} \ln c(t) d t= \\
& =\int_{0}^{+\infty} e^{-\rho t}(\ln f(k(t))+\ln (1-u(t))) d t,
\end{aligned}
$$

where $\rho$ is the discount factor.

Let us note that in the utility theory, the logarithmic function describes the relative increase (in our case - the relative consumption) per unit of time. Under conditions of uncertainty the logarithmic function specifies the constant relative risk aversion.

Problem. It is necessary to construct such an investment strategy $(k(t), u(t))$ that satisfies the constraints (2) and maximizes the objective func- tional (4) on trajectories of the dynamical system (3).

\section{Analysis of the optimal control problem within the framework of Pontryagin's maximum principle}

The posed problem of optimal control is subject to a modification of Pontryagin's maximum principle for the infinite time period [3-11].

Let us construct the stationary Hamiltonian function of the control problem which due to the dynamics (3) and the objective functional of the control process (4) has the following form with the conjugate variable $\psi$

$$
H(k, \psi, u)=\ln f(k)+\ln (1-u)+\psi(u f(k)-\delta k) .
$$

Let us calculate the control $u^{0}$, delivering maximum to the Hamiltonian $H(5)$

$$
\Rightarrow u^{0}(k, \psi)=\left\{\begin{array}{lr}
\frac{\partial H(k, \psi, u)}{\partial u}=-\frac{1}{1-u}+\psi f(k) \Rightarrow \\
1-\frac{1}{f(k) \psi}, & 1 \leq f(k) \psi \leq \frac{1}{1-\bar{u}}, \\
\bar{u}, & f(k) \psi \geq \frac{1}{1-\bar{u}} .
\end{array}\right.
$$

The maximum control $u^{0}(k, \psi)$ (6) divides the domain of variables $(k, \psi)$ into three domains with the different structure of the Hamiltonian dynamics defined by relations

$$
\begin{aligned}
& \frac{d k(t)}{d t}=\frac{\partial H\left(k(t), \psi(t), u^{0}(k(t), \psi(t))\right)}{\partial \psi}= \\
& =u^{0}(k(t), \psi(t)) f(k(t))-\delta k(t),
\end{aligned}
$$

$$
\begin{aligned}
& \frac{d \psi(t)}{d t}=\rho \psi(t)-\frac{\partial H\left(k(t), \psi(t), u^{0}(k(t), \psi(t))\right)}{\partial k}= \\
& =\rho \psi(t)-\frac{f^{\prime}(k)}{f(k)}-\psi(t)\left(u^{0}(k(t), \psi(t)) f^{\prime}(k(t))-\delta\right) .
\end{aligned}
$$

Let us consider the Hamiltonian system (7) for three different control modes.

\section{Zero control mode}

The domain of the zero control mode $u^{0}(k, \psi)=0$ is determined by the relations $0<f(k) \psi \leq 1$. The Hamiltonian system with this control can be written as

$$
\begin{gathered}
\frac{d k(t)}{d t}=-\delta k(t), \\
\frac{d \psi(t)}{d t}=(\rho+\delta) \psi(t)-\frac{f^{\prime}(k)}{f(k)} .
\end{gathered}
$$


Passing to the normalized dynamics, we obtain the system of differential equations in variables $(k, z)$ where $z=k \psi$

$$
\begin{gathered}
\frac{d k(t)}{d t}=-\delta k(t), \\
\frac{d z(t)}{d t}=\rho z(t)-\frac{f^{\prime}(k)}{f(k)} k=\rho z(t)-\alpha .
\end{gathered}
$$

As one can see from the structure of the system (8), its solution declines exponentially to zero at the rate of depreciation of fixed assets $\delta$ with respect to the phase component of capital $k(t)$. Thus, the lack of the investment component leads to reduction of the capital stock up to the zero level.

\section{Transient control mode}

The transient control mode is characterized by a non-zero share of output invested in fixed assets that is calculated by the formula

$$
u^{0}(k, \psi)=1-\frac{1}{f(k) \psi}=1-\frac{k}{f(k) z}, \quad z=k \psi
$$

and meets restrictions: $1 \leq \frac{f(k) z}{k} \leq \frac{1}{1-\bar{u}}$.

The Hamiltonian system in the variable control mode has the following structure

$$
\begin{gathered}
\frac{d k(t)}{d t}=\left(\frac{f(k(t))}{k(t)}-\frac{1}{z(t)}-\delta\right) k(t), \\
\frac{d z(t)}{d t}=\left(\rho-f(k(t))+\frac{f(k(t))}{k(t)}\right) z(t)-1= \\
=\left(\rho+(1-\alpha) \frac{f(k(t))}{k(t)}\right) z(t)-1 .
\end{gathered}
$$

\section{Saturated control mode}

The saturated control mode is presented by the highest possible level of investments in fixed assets $u^{0}(k, \psi)=\bar{u}$, and is constrained by the limitations $f(k) \psi \geq 1 /(1-\bar{u})$. Under these conditions, the Hamiltonian system $(7)$ in the variable $(k, z)$ has the following form

$$
\begin{gathered}
\frac{d k(t)}{d t}=\left(\bar{u} \frac{f(k(t))}{k(t)}-\delta\right) k(t), \\
\frac{d z(t)}{d t}=\left(\rho-\bar{u} f^{\prime}(k(t))+\bar{u} \frac{f(k(t))}{k(t)}\right) z(t)- \\
-\frac{f^{\prime}(k(t)) k(t)}{f(k(t))}=\left(\rho+\bar{u}(1-\alpha) \frac{f(k(t))}{k(t)}\right) z(t)-\alpha .
\end{gathered}
$$

In the last formulas, we use the following properties of the Cobb-Douglas production function of the exponential type:

$$
f^{\prime}(k)=a \alpha k^{\alpha-1}=\alpha \frac{a k^{\alpha}}{k}=\alpha \frac{f(k)}{k} \Rightarrow \frac{f^{\prime}(k) k}{f(k)}=\alpha .
$$

\section{Equilibrium of economy in the maximum principle}

Stationary levels of the Hamiltonian system (7) determine the equilibrium positions of the economic system. In order to find these levels we equate the right sides of the Hamiltonian systems (8)-(10) to zero and solve the system of non-linear algebraic equations in variables $(k, z)$ under conditions $k>0, z>0, \psi>0$.

Evidently, the Hamiltonian system (8) for the zero control regimes does not have stationary levels satisfying the constraints $k>0, z>0$. However, in domains of the transient and saturated control regimes steady states exist and their coordinates are determined analytically through the model parameters.

Proposition. The equilibrium points in the domain of the transient control and the domain of the saturated control are given by the formulas

$$
\begin{gathered}
k^{*}=\left\{\begin{array}{c}
\left(\frac{a \alpha}{\delta+\rho}\right)^{\frac{1}{1-\alpha}}, u^{*}=\frac{\alpha \delta}{\delta+\rho}<\bar{u}, \\
\left(\frac{\bar{u} a}{\delta}\right)^{\frac{1}{1-\alpha}}, \quad u^{*}=\bar{u},
\end{array}\right. \\
z^{*}=\frac{\alpha}{\rho+(1-\alpha) \delta}, y^{*}=a\left(k^{*}\right)^{\alpha}, \\
c^{*}=y^{*}\left(1-u^{*}\right) .
\end{gathered}
$$

Proof. 1) Let us calculate the coordinates of the equilibrium point in the transient control regime. It is necessary to equate the right sides of the Hamiltonian system (9) to zero

$$
\begin{gathered}
\frac{f(k)}{k}-\frac{1}{z}-\delta=0 \Rightarrow \frac{f\left(k^{*}\right)}{k^{*}}=\delta+\frac{1}{z^{*}}, \\
\left(\rho+(1-\alpha) \frac{f(k)}{k}\right) z-1=0 \Rightarrow \\
\Rightarrow\left(\rho+(1-\alpha)\left(\delta+\frac{1}{z}\right)\right) z=1, \\
z^{*}=\frac{\alpha}{\rho+(1-\alpha) \delta} \Rightarrow \frac{f\left(k^{*}\right)}{k^{*}}=\frac{\rho+\delta}{\alpha} \Rightarrow \\
\Rightarrow k^{*}=\left(\frac{a \alpha}{\delta+\rho}\right)^{\frac{1}{1-\alpha}} \cdot
\end{gathered}
$$


Let us calculate the control value corresponding to the equilibrium level

$$
u^{*}=1-\frac{k^{*}}{f\left(k^{*}\right) z^{*}}=1-\frac{\alpha(\rho+(1-\alpha) \delta)}{(\rho+\delta) \alpha}=\frac{\alpha \delta}{\delta+\rho}<1 .
$$

The equilibrium point is located in the domain of the transient control if $u^{*}<\bar{u}$. Therefore, if the model parameters meet the constraints

$$
\frac{\alpha \delta}{\delta+\rho}<\bar{u},
$$

the equilibrium point $\left(k^{*}, z^{*}, u^{*}\right)$ is attained in the domain of the transient control.

2) Let us calculate the coordinates of the equilibrium point in the domain of the saturated control when $u(t)=\bar{u}$. In order to do this, one should resolve the system of nonlinear algebraic equations determined by the right hand sides of the Hamiltonian dynamics (10)

$$
\begin{gathered}
\bar{u} \frac{f(k)}{k}-\delta=0 \Rightarrow \frac{f\left(k^{*}\right)}{k^{*}}=\frac{\delta}{\bar{u}} \Rightarrow k^{*}=\left(\frac{a \bar{u}}{\delta}\right)^{\frac{1}{1-\alpha}}, \\
\left(\rho+\bar{u}(1-\alpha) \frac{f(k)}{k}\right) z-\alpha=0 \Rightarrow \\
\Rightarrow(\rho+(1-\alpha) \delta) z^{*}=\alpha \Rightarrow \\
\Rightarrow z^{*}=\frac{\alpha}{\rho+(1-\alpha) \delta} .
\end{gathered}
$$

The equilibrium control coincides with the maximum possible investment level into capital, i.e. $u^{*}=\bar{u}$.

The equilibrium level of the output is calculated by the formula (1)

$$
y^{*}=f\left(k^{*}\right)=a\left(k^{*}\right)^{\alpha} \text {. }
$$

The equilibrium level of consumption, expressed through the balance equation, is given by the following relation

$$
c^{*}=\left(1-u^{*}\right) y^{*} \text {. }
$$

Proposition is proved.

Analytical expressions for the values of investment $u^{*}$, capital $k^{*}$, output volume $y^{*}$ and consumption $c^{*}$ allow to analyze the sensitivity of the stationary equilibrium state in terms of the elasticity coefficients for the model parameters $\alpha, \delta, \rho$. Signs of elasticity coefficient indicate of the growth and decrease trends. Their absolute values indicate the change rates in percentage terms.

Calculation of the logarithmic values of derivatives of investments $k^{\prime \prime}$ at the equilibrium point provides the following values for the elasticity coefficients with respect to the model parameters

$$
\begin{gathered}
\varepsilon_{u, \alpha}=\frac{\alpha}{u^{*}} \frac{\partial u^{*}}{\partial \alpha}=1, \varepsilon_{u, \delta}=\frac{\delta}{u^{*}} \frac{\partial u^{*}}{\partial \delta}=\frac{\rho}{\delta+\rho}<1, \\
\varepsilon_{u, \rho}=\frac{\rho}{u^{*}} \frac{\partial u^{*}}{\partial \rho}=-\frac{\rho}{\delta+\rho}<0 .
\end{gathered}
$$

Coefficients of elasticity show that the equilibrium investments in capital $u^{*}$ increases together with the growing elasticity $\alpha$ of the production function and the growing capital depreciation rate $\delta$, and it decreases when the discount factor pincreases.

Elasticity coefficients for the equilibrium output of production $y^{*}$ with the respect to the model parameters have the following expressions

$$
\begin{aligned}
& \varepsilon_{y, \alpha}=\frac{\alpha}{y^{*}} \frac{\partial y^{*}}{\partial \alpha}=\frac{\alpha}{1-\alpha}\left(1+\frac{\ln \alpha}{1-\alpha}\right), \\
& \varepsilon_{y, \delta}=\frac{\delta}{y^{*}} \frac{\partial y^{*}}{\partial \delta}=-\frac{\alpha}{1-\alpha} \cdot \frac{\delta}{\delta+\rho}<0, \\
& \varepsilon_{y, \rho}=\frac{\rho}{y^{*}} \frac{\partial y^{*}}{\partial \rho}=-\frac{\alpha}{1-\alpha} \cdot \frac{\rho}{\delta+\rho}<0 .
\end{aligned}
$$

Negative signs of the elasticity of the equilibrium production level $y^{*}$ with respect to changes in the capital depreciation rate $\delta$ and the discount factor $\rho$ indicate the decline trend. As for the sign of the elasticity of the equilibrium production level $y^{*}$ with respect to changes in the elasticity $\alpha$ of the production function, it is worth to note that small values of the elasticity $\alpha$ make it negative and large values of the elasticity of a make it positive. It means that here both decreasing and increasing trends can be obtained.

If the equilibrium level of capital satisfies the constraint $u^{*}<\bar{u}$, then one can observe the decline trend over time of the optimal investments to the level of $u^{*}$. Otherwise, the maximum level of investments is the best possible value on the entire time interval until the time of stabilization of the dynamical system. In all development scenarios the pattern of optimal solutions is configured in the expressed S-shape, which is ensured by the presence of the parameter constraints $\bar{u}$ on investments $u(t)$. In addition, one can note that the optimal trajectories have a tendency to the saturation growth.

\section{An algorithm for constructing optimal model trajectories}

Let us give a brief description of the algorithm for constructing the optimal trajectories as solutions of the Hamiltonian systems (8)-(10). We should note the integration peculiarity of the Hamiltonian systems, which involves boundary conditions for the phase variable of capital $k(t)$, given on the left side, and the boundary condi- 
tions for the adjoint variable $z(t)$ are given on the right side of the time interval. In this connection, a two-step integration procedure is developed.

1 . The first step. The system is integrated by the Runge-Kutta method in the reverse time from the equilibrium point in the direction of the eigenvector of the Jacobian matrix corresponding to the negative eigenvalue. Integration is implemented until the integrated trajectory reaches the initial point of the phase variable.

2. The second step. Integration is performed in the direct timeline from the initial point. During this process, the components of the optimal model trajectory are reconstructed including the optimal investment plan $u^{0}(t)$.

It is important to emphasize that the two-step integration process provides a highly accurate algorithm for constructing optimal model trajectory with the order higher than the time step of integration.

\section{Econometric analysis of the parameters of the production function}

It is worth to emphasize that construction of prognostic model trajectories and econometric analysis of the production function and other parameters of the model are complementary tasks, but they are carried out in separate blocks with different functions. The econometric analysis is based on the classical methods of econometrics [15-16] and is used to identify the model parameters, in particular, the elasticity coefficients of the production function and setting the total factor productivity. The numerical algorithms, after substituting parameters identified in the econometric analysis, work offline producing optimal trajectory of endogenous growth. Another important issue is that the simulation procedure does not attempt to construct the trajectories of the best approximation of the real time series. It builds namely the optimal investment plan and the optimal trajectory of economic growth. If the optimal model trajectory is close to the real data of economic development, then this fact indicates the optimal economic growth of the analyzed economic system in the sense of the integral consumption index. In the case of deviations of the optimal model trajectory from the data in the "upper" or "lower" direction, it is reasonable to discuss a phenomenon of underinvestment or overinvestment in the economic system. In this context, the model constructs the optimal investment plan that indicates imbalances with the real data. Therefore, the model trajectories could be called optimal prognostic trajectories to distinguish them from forecasts of econometric models.

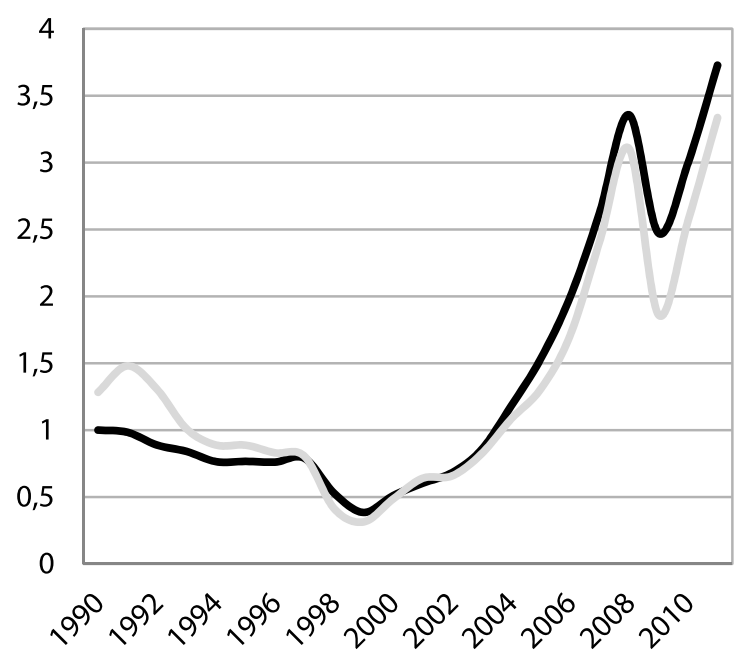

Fig. 1. Comparison of real data and predictive values of GDP (black) on the simple regression model (grey)

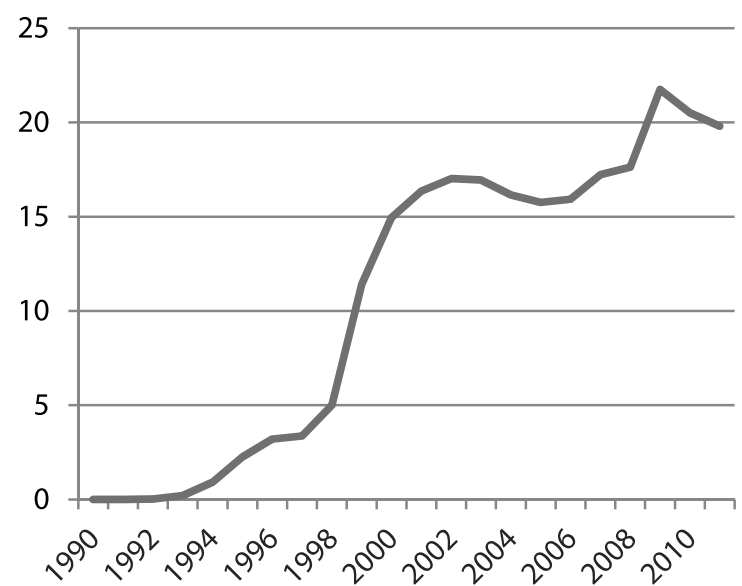

Fig. 2. Share of GDP invested in fixed capital, $u, \%$

The calibration procedure for the production function (1) is fulfilled on the basis of the statistical data [17-18] of the Russian economy in the period from 1990 to 2011 using the paired-regression model

$$
w_{i}=\alpha x_{i}+\beta \text {, }
$$

where $w_{i}=\ln y_{i}, x_{i}=\ln k_{i}, \beta=\ln a, i=\overline{1,22}$.

Estimates of the paired-regression model parameters are calculated by the least squares method:

$$
\begin{aligned}
\hat{\alpha}=\frac{\operatorname{cov}(w, x)}{\sigma^{2}(x)} & =0,836, \hat{\beta}=\bar{w}-\hat{\alpha} \bar{x}=0,249 \Rightarrow \\
& \Rightarrow \hat{y}=1,283 k^{0,836} .
\end{aligned}
$$

Curves on Figure 1 show the real data (in black) and the trajectory constructed using the regression model (in grey).

To assess the quality of the regression model the coefficient of determination $R^{2}=0,909$ is calculated whose value indicates a good "matching" with the real data. The results of testing the significance hypothesis of the regression model suggest that the fixed capital has a significant impact on 
the level of country's GDP, and this is confirmed by the following calculation:

1. Evaluation of the error variance: $s^{2}=\frac{1}{N-2} \sum e_{i}^{2}=0,03$.

2. Evaluation of the variance for the elasticity coefficient, $\hat{\sigma}^{2}(\hat{\alpha})$ :

$$
\hat{\sigma}^{2}(\hat{\alpha})=\frac{s^{2}}{\sum\left(x_{i}-\bar{x}\right)}=0,0032 .
$$

3. The observed value of the Student's statistics for $N-2=20$ degrees of freedom:

$$
t=\frac{\hat{\alpha}}{\hat{\sigma}(\hat{\alpha})}=14,86 \text {. }
$$

4. The critical value at the level of the statistical reliability, $\gamma=95 \%$ :

$$
t_{k}=t_{\frac{1-\gamma}{2}}(N-2)=2,086 \Rightarrow t>t_{k} .
$$

\section{Prognostic model trajectories and comparison with econometric time series}

Returning to the described model of economic growth, let us construct its solutions numerically [4-11], and compare these solutions with real data. To construct the prognostic trajectories we use results of the regression analysis for the production function, as well as data on the Russian economy for the period from 1990 till 2011 [17-18]. The estimated indices of economic development are calculated at the levels:

$$
k^{*}=5.97, y^{*}=5.74, u^{*}=0.443, c^{*}=3.195,
$$

taking into account the economic indicators [1718 ] given in the list.

1. The level of depreciation of fixed assets according to Rosstat [18] is estimated as $42 \%$ in average, thus, the parameter $\mu$ is equal to 0.42 .

2 . The growth rate of the labor force $n$ is estimated at the level of 0.004 in the period from 1990 to 2011.

3. The discount factor $\rho$ according to the data [18] of the Central Bank of the Russian Federation on the refinancing rate is fixed at the level of 0.08 .

4. The level of investments in fixed assets, according to Rosstat [18] has a clearly expressed increasing trend (see Figure 2). Therefore, to construct the prognostic trajectory the maximum level of investments $\bar{u}$ is chosen at a sufficiently high level of $44.3 \%$. However, even the investment limit of $44.3 \%$ does not meet the inequality

$$
\frac{\alpha \delta}{\delta+\rho}=0,703<\bar{u} .
$$

This fact indicates that the investment trajectory does not decrease during the forecast period.
And selection of a smaller value $\bar{u}$ for the maximum investment level leads to the economy with practically zero growth.

The model shows that the optimal level of investments in the Russian economy in the current period is implemented on the upper level of constraints. Let us note that a series of experiments, with different restrictions on the maximum level of investments have been conducted and the outcome remained the same: the optimal level of investments is realized at the upper limit. This means that investments in fixed assets in the economy are insufficient and require increase even for the upper threshold. For comparison, in modeling developed economies such as economies of the US [8-11], Japan [4-7], and the UK [4-5], one can observe a qualitatively different picture. Namely, the model investment plans have the tendency to decrease to the stationary equilibrium level $u^{*}<\bar{u}$, which indicates the situation of over-investment in fixed assets in these countries.

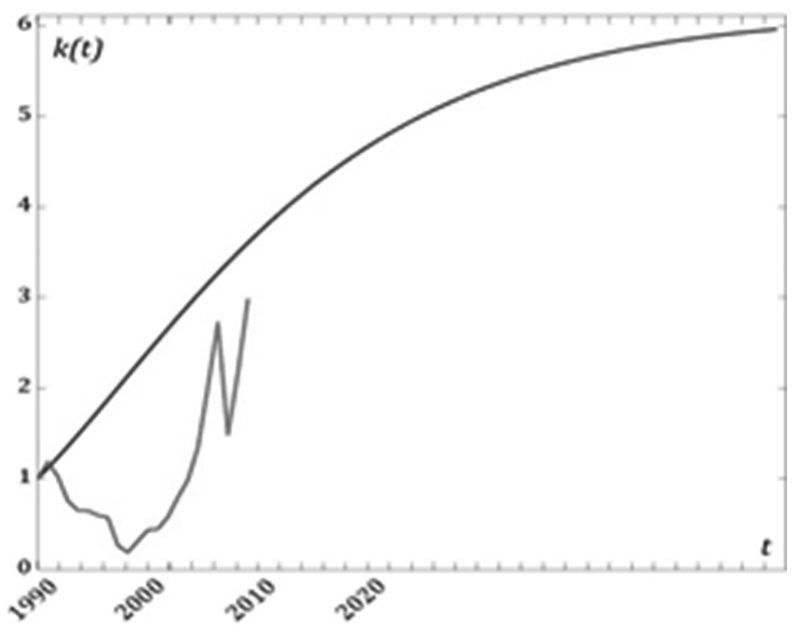

Fig. 3. Prognostic growth rates (black) of fixed capital per capita of working population in comparison with real data (grey)

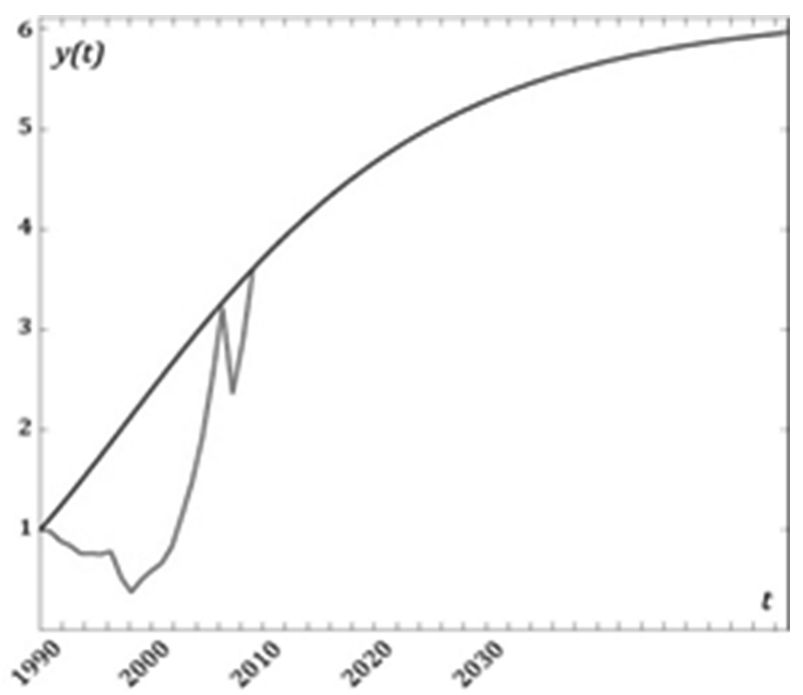

Fig. 4. Prognostic growth rates (black) of GDP per capita of working population in comparison with real data (gray) 
On Figures 3 and 4 the prognostic model trajectories of the Russian economic development with projections to 2050 are presented in comparison with the real data.

The presented plots clearly indicate that in the 90th years there is a rapid reduction in production and investments in fixed assets, which is expressed in sharp drops of real statistical trends. At the same time, the prognostic model trajectories clearly demonstrate a growing trend, since the model is inherently focused on the search for such an investment strategy that leads the economy to the growth domain. The investments growth is positively reflected in the statistics of the dynamics, as one can see on the presented graphs. Namely, starting from 2000 clear growth trends are shaped for the main considered factors (excepting the recession of 2008), and by the end of the analyzed period the actual data almost reach the model trends.

It should be noted that the comparative analysis of modeling results for the macroeconomic data on countries' economies in different groups shows that the values of the identified model parameters in these groups are qualitatively different by clusters. These differences affect, first of all, the dynamics of investment plans. In economies of developed countries, one can observe the decline trend in investments (in percentage) with higher initial levels to lower stationary equilibrium levels. For economies of developing countries there is a bifurcation and qualitatively different trends are observed when the value of the equilibrium investments is very high in comparison with the actual current levels. This leads to the situation when the model optimal investments should reach the highest possible limit values.

\section{Conclusion}

The paper deals with analysis of the model of economic growth within the framework of the optimal control theory. The problem of optimizing the investment levels is considered, the solutions are constructed within the Pontryagin maximum principle, and analysis of trends is fulfilled for the optimal model trajectories. Identification of parameters and analysis of significance of the regression model are implemented for the production function. Basing on algorithms for numerical construction of optimal prognostic trajectories, the model growth trends are identified; equilibrium points of major economic indicators are calculated and compared with real statistical data of the Russian economy. Major differences are indicated between the identified trends and the growth trajectories in developed economies.

The study is supported by the grant of the Russian Scientific Fund (project No. 14-18-00574 "Information and analytical "Anticrisis" system: diagnostics of regions, threat assessments, and scenario forecasting for the purpose of maintaining and strengthening of economic security and improve welfare of Russia").

\section{References}

1. Solow, R. M. (1970). Growth Theory: An Exposition. NY, Oxford Univ. Press, 190.

2. Pontryagin, L. S., Boltyanskiy, V. G., Gamkrelidze, R. V. \& Mishchenko, E. F. (1962). Matematicheskaya teoriya optimalnykh [The Mathematical Theory of Optimal Processes], Interscience, New York, 363.

3. Aseyev, S. M., Kryazhimskiy, A. V (2007). The Pontryagin Maximum Principle and Optimal Economic Growth Problems. Proceedings of the Steklov Institute of Mathematics. Pleiades Publishing, Vol. 257, 1, 5-271.

4. Krasovskiy, A. \& Tarasyev, A. (2008). Conjugation of Hamiltonian Systems in Optimal Control Problems. Proceedings of the 17th IFAC World Congress, 17, 1, COEX, Korea, South, 7784-7789. DOI: 10.3182/20080706-5-KR-1001.01316.

5. Krasovskiy, A., Kryazhimskiy, A. \& Tarasyev, A. (2008). Optimal Control Design in Models of Economic Growth. Evolutionary Methods for Design, Optimization and Control (P. Neittaanmäki, J. Périaux and T. Tuovinen, Eds.), CIMNE, Barcelona, Spain, $70-75$.

6. Krasovskiy, A. A. \& Tarasyev, A. M. (2008). Svoystva gamiltonovykh system v printsipe maksiuma Pontryagina dlya zadach ekonomicheskogo rosta [Properties of Hamiltonian Systems in the Pontryagin Maximum Principle for Economic Growth]. Trudy matematicheskogo institute im. Steklova V.A. [Proceedings of the Steklov Mathematical Institute], 262, 127-145.

7. Krasovskiy, A. A. \& Tarasyev, A. M. (2009). Postroyenie nelineynykh regulyatorov v modelyakh ekonomicheskogo rosta [Construction of Nonlinear Stabilizers in Economic Growth Models]. Trudy Instituta matematiki i mekhaniki [Proceedings of the Institute of Mathematics and Mechanics], Yekaterinburg: Ural Branch of RAS, Vol. 15, 3, 127-138.

8. Tarasyev, A. M. \& Usova, A. A. (2011). The Value Function as a Solution of Hamiltonian Systems in Linear Optimal Control Problems with Infinite Horizon. Proceedings of the 18th IFAC World Congress, Milan, Vol. 18, Part 1, 2927-2933.

9. Tarasyev, A. M. \& Usova, A. A. (2010). Postroyenie regulyatora dlya gamiltonovoy sistemy dvukhsektornoy modeli ekonomicheskogo rosta [Developmet of a Stabilizer for the Hamiltonian system of a Two-Sector Model of Economic Growth]. Trudy matematicheskogo instituta im. V. A. Steklova [Proceedings of the Steklov Mathematical Institute], 271, 278-298.

10. Tarasyev, A. M. \& Usova, A .A. (2012). Stabilizatsiya gamiltonovoy sistemy dlya postroyeniya optimalnykh trayektoriy [Stabilization of Hamiltonian systems for Constructing Optimal Trajectories]. Trudy matematicheskogo instituta [Proceedings of the Steklov Mathematical Institute], 277, 257-274.

11. Usova, A. A. (2012). Ob asimptoticheskikh svoystvakh optimalnykh resheniy i funktsiy tseny v zadachakh optimalnogo upravleniya na beskonechnom gorizonte. [On the Asymptotic Properties of Optimal Solutions and Value Functions in Optimal Control Problems on Infinite Horizon]. Vestnik Udmurtskogo Universiteta. Matematika. Mekhanika. Kompyuternyye nauki [Bulletin of the Udmurt University. Mathematics. Mechanics. Computer Science], 1, 77-95. 
12. Intriligator, M. (1971). Matematicheskie metody optimizatsii i ekonomicheskaya teoriya [Mathematical Optimization and Economic Theory]. Prentice-Hall, N.Y., 553.

13. Krushvits, L.(1995). Finansirovanie i invistitsii [Finanzierung und Investition] . Walter De Gruyter Inc., Berlin, 400.

14. Sharpe, W. F., Alexander, G. J. \& Bailey J. V. (1999). Investitsii [Investments]. Sixth Edition. Prentice-Hall, N.Y., 965.

15. Ayvazyan, S. A. (2010). Metody ekonometriki [Methods in Econometrics]. Moscow: INFRA-M, 512.

16. Magnus, Y. R., Katyshev, P. K. \& Peresetskiy, A. A. (2007). Ekonometrika [Econometrics]. Moscow: DELO, 580.

17. OECD Statistics. Available at: http://stats.oecd.org, 2012.

18. Federalnaya sluzhba gosudarstvennoy statistiki RF (FSGS RF) [Federal State Statistics Service (Rosstat)]. Available at: http:// www.gks.ru/wps/wcm/connect/rosstat_main/rosstat/ru/statistics.

\section{Information about the authors}

Tarasyev Alexander Mikhajlovich (Yekaterinburg, Russia) - Dr. Phys.-Math. Sci., Head of Sector, the Institute of Mathematics and Mechanics named after N. N. Krasovskii of the Ural Branch of the Russian Academy of Sciences; Research Scholar, International Institute for Applied Systems Analysis (IIASA) (16, S. Kovalevskaya str., Yekaterinburg, 620990, Russia, e-mail: tam@imm.uran.ru).

Usova Anastasy Aleksandrovna (Yekaterinburg, Russia) - PhD in Phys.-Math. Sci., Research Scholar, the Institute of Mathematics and Mechanics named after N.N. Krasovskii of the Ural Branch of the Russian Academy of Sciences (16, S. Kovalevskaya str., Yekaterinburg, 620990, Russia, e-mail: anastasy.ousova@gmail.com).

Shmotina Yulia Valer'evna (Yekaterinburg, Russia) - student, the Institute of Mathematics and Computer Science, the Ural Federal University named after the first President of Russia B.N. Yeltsin (19, Mira str., Yekaterinburg, 620002, Russia, e-mail: juliashmotina@yandex.ru). 